\title{
Large Population and Unhygienic Conditions are "Blessings in Disguise" Amid Asian Countries for Low Infection Rate of COVID-19 as Compared to
} Europe and America

\author{
Muhammad Mujahid Khan, MD, PhD ${ }^{* 1}$, Sadia Wazir Khan, MD, M. Phil ${ }^{1}$, Mohammed Moizuddin Khan, \\ MD, PhD ${ }^{1}$, Tahani Nasser Altamimi, MD, PhD ${ }^{2,3}$, Shifa Khan, $\mathrm{MD}^{4}$, Saleh Sulaiman Alnajashi ${ }^{5}$, Mahdi Al- \\ Ameer ${ }^{5}$, Meshari Talal Alanazi ${ }^{5}$, Abdulaziz Al-Hamidi, PhD ${ }^{1}$ \\ ${ }^{1}$ Department of Basic Medical Sciences, College of Medicine, Dar Al Uloom University, Riyadh, Saudi Arabia \\ ${ }^{2}$ Department of Family and Community Medicine, College of Medicine, University of Hail, Hail, Saudi Arabia \\ ${ }^{3}$ Department of Family and Community Medicine, College of Medicine, Dar Al Uloom University, Riyadh, \\ Saudi Arabia \\ ${ }^{4}$ National Medical University, Islamabad, Pakistan \\ ${ }^{5}$ College of Medicine, Dar Al Uloom University, Riyadh, Saudi Arabia
}

*Correspondence should be addressed to: Muhammad Mujahid Khan, MD, PhD

Professor, Department of Basic Medical Sciences, College of Medicine, Dar Al Uloom University, P.O. Box 45142.

Riyadh 11512, Saudi Arabia; dralkhan@hotmail.com,m.mujahid@dau.edu.sa

Received 01 October 2021;

Accepted 26 October 2021;

Published 01 November 2021

\begin{abstract}
This epidemiological cross-sectional data-based study aimed to explore the morbidity and mortality patterns of novel coronavirus infections (COVID-19) among the worst affected regions of the world. The data on the worldwide pandemic of COVID-19 were obtained from World Health Organization (WHO), John Hopkin's University research center, Worldometer, Centers for Disease Control and Prevention (CDC), since its outbreak until August 5, 2020. The evidences were also recorded from research papers published in international scientific journals indexed in Pub Med and Institute of Scientific Information (ISI) Web of Science.

The findings show that the average of COVID-19 cases in Europe is 154754 cases per million of the population, in America (both north and south) is 47982 cases per million of the population and in Asia is 13280 cases per million of the population. The mean value of mortality rate in Europe, America (both north and south) and Asia is 2436 deaths per million of population, 2158 deaths per million of population, and 181 deaths per million people, respectively.

The study broadly concludes that the infection rate and mortality are higher in developed countries than in developing or underdeveloped countries. The perceptible causes of increase in infection rate and mortality in developed European and American countries may be the difference in individual and herd immunity in the population due to less exposure to similar viruses. The lack of exposure may be attributed to better economic conditions leading to relatively good hygienic practices as compared to the developing and underdeveloped countries of the Asian region.
\end{abstract}

Keywords: morbidity; prevalence; mortality; epidemiological characteristics; outbreak

\section{Introduction}

In December 2019, reports emerged from Wuhan, China, of a severe acute respiratory disease caused by coronavirus 2 (SARSCoV-2). By the end of April 2020, over 3 million people had been confirmed to be infected, with over 1 million in USA alone, and over 215000 deaths ${ }^{[1]}$. The WHO declared this as a Public Health Emergency of International Concern (PHEIC) on January 31, 2020, and finally a pandemic on March 11, $2020^{[2]}$. Initially, it emerged as a series of pneumonia cases of unknown cause that emerged in Wuhan, Hubei, China ${ }^{[3]}$. COVID-19, also known as SARS-CoV-2, is a new emerging zoonotic corona virus of the severe acute 
respiratory syndrome (SARS) and Middle East Respiratory Syndrome (MERS) family ${ }^{[4]}$. COVID-19 shows a substantially advanced mortality proportion in advanced age patients and has affected a large population in over 200 countries.

COVID-19 is highly contagious and to protect oneself and social distancing is recommended by health organizations. It has caused negative social and psychological effects, as it has undisputedly dented global economies evident by the indicators from the various stock markets ${ }^{[5]}$. Initially, it was supposed that COVID-19 is a threat to China, but due to its high contagious capability and varied mortality, it has become a public health emergency for the whole world. It is considered as a major source of disaster in the $21^{\text {st }}$ century ${ }^{[6]}$. But there are still controversies about the source of the virus and its intermediate host ${ }^{[7]}$. An abrupt rise in the total number of infection cases and mortality caused frustration and panic situations in the world. In a pandemic like this, providing timely and accurate information is paramount.

According to the data available on WHO websites, and worldometer ${ }^{[2]}$, it is observed that some countries are affected worst and others are less, and the difference seems to be at the regional level of the world, which led us to think why it is so.

Therefore, this epidemiological study is intended with an aim to explore the morbidity and mortality pattern of novel coronavirus (COVID-19) infections amongst the worst affected regions of the world.

\section{Materials and Methods}

This study was conducted at the Basic Sciences Department, College of Medicine, Dar Al Uloom University (IRB Approval number: Pro21010010). Data on the incidence and mortality due to the COVID-19 pandemic were acquired from the World Health Organization, countries and regions and their concerned ministries and Worldometer; hence, informed consent was not required. This is a cross-sectional data-based study done on three worst hit regions affected by COVID -19 i.e., Europe, America and Asia. From each region, the top five countries with the highest infection rate, with more than 500 cases per million of a population. The data were collected until August 5, 2020. The infection rate and mortality data were acquired from the World Health Organization (WHO), Centers for Disease Control and Prevention (CDC), and information from several countries and their associated agencies. Data were procured from search engines including Worldometer Coronavirus. Furthermore, we reviewed the literature published in the Institute of Scientific Information (ISI) Web of Knowledge. Thomas Reuters, Pub-Med, Medline, and the findings were documented.

\section{Statistical Analysis}

The results were recorded, compared, and analyzed using SPSS version 18.0. Significance among the groups was tested by comparing means using one-way ANOVA and post hoc Tukey's test for the descriptive statistics between the groups. The results are expressed as means. The comparison analysis was performed, and a $p$-value $\leq 0.05$ was considered significant. A p-value $\leq 0.001$ was considered highly significant.

\section{Results}

It was observed that the average number of cases of COVID-19 in Europe is 154754 cases per million of the population, in America (both north and south) is 47982 per million of the population and in Asia is 13280 per million of the population (see Table $\mathbf{1}$ and Figure 1).

Similarly, the mortality rates in Europe, America (both north and south), and in Asia were 2436 deaths per millions of population, 2158 deaths per million of population, and 181 deaths per million of the population, respectively (see Table 1 and Figure 1).

The infection and mortality rates were compared among the regions; the difference between the number of cases per million population between Europe and America was significant with a pvalue of 0.002 , and between Asia and Europe it was found to be highly significant with a p-value of 0.000 ; however, the numbers reflect less infection and mortality rates in Asia compared to America, but the difference could not be substantiated by statistical test, and hence found to be non-significant with a p-value of 0.35 (see Table 2).

The mean difference in mortality per million populations among the regions was found to be significant between America and Asia and between Asia and Europe, with p-values of 0.004 and 0.002 , respectively. However, this difference was not significant between the European and American p-values 0.841 (see Table 2).

Moreover, the number of cases and mortality rate per million populations of each country included in the abovementioned three regions are also listed in Table 3.

Table 1: Mean value of COVID-19 cases and deaths in Europe, America (both north and south) and Asia per million of the population

\begin{tabular}{|l|l|l|l|l|}
\hline Variable & Europe & America & Asia \\
\hline No. of Cases per million population & Mean values & 154754 & 47982 & 13280 \\
\hline No. of Deaths per million population & Mean values & 2436 & 2158 & 181 \\
\hline
\end{tabular}

Table 2: Mean difference between no. of COVID-19 cases and no. of mortalities per million of the population between Europe, America (both north and south) and Asia

\begin{tabular}{|l|l|l|l|l|}
\hline Variable & Europe - America & America - Asia & Asia - Europe \\
\hline \multirow{2}{*}{ No. of Cases per million population } & Mean Difference & 21354.4 & 6940.4 & 28294.8 \\
\cline { 2 - 5 } & p-value & 0.002 & 0.35 & 0.000 \\
\hline \multirow{2}{*}{ No. of Deaths per million population } & Mean Difference & 55.6 & 395.4 & 451.0 \\
\cline { 2 - 4 } & p-value & 0.841 & 0.004 & 0.002 \\
\hline
\end{tabular}

Table 3: Number of cases and mortality rate per million population of each country of the regions included in the study

\begin{tabular}{|l|l|l|l|}
\hline Regions & Countries & No. of cases per million population & No. of Deaths per million population \\
\hline \multirow{3}{*}{ EUROPE } & Russia & 14490 & 99 \\
\cline { 2 - 4 } & Spain & 28498 & 609 \\
\cline { 2 - 4 } & UK & 46299 & 682 \\
\hline
\end{tabular}


International Journal of Innovative Research in Medical Science (IJIRMS)

\begin{tabular}{|l|l|l|l|}
\hline \multirow{4}{*}{ AMERICA } & Italy & 35171 & 582 \\
\cline { 2 - 4 } & France & 30296 & 464 \\
\hline & USA & 14852 & 484 \\
\cline { 2 - 4 } & Mexico & 3486 & 379 \\
\cline { 2 - 4 } & Canada & 3118 & 237 \\
\cline { 2 - 4 } & Brazil & 13202 & 452 \\
\cline { 2 - 4 } & Peru & 13324 & 606 \\
\hline \multirow{4}{*}{ SSIA } & India & 1383 & 29 \\
\cline { 2 - 4 } & Pakistan & 1271 & 27 \\
\cline { 2 - 4 } & Bangladesh & 1496 & 20 \\
\cline { 2 - 4 } & KSA & 8073 & 86 \\
\cline { 2 - 4 } & Philippines & 1057 & 19 \\
\hline
\end{tabular}
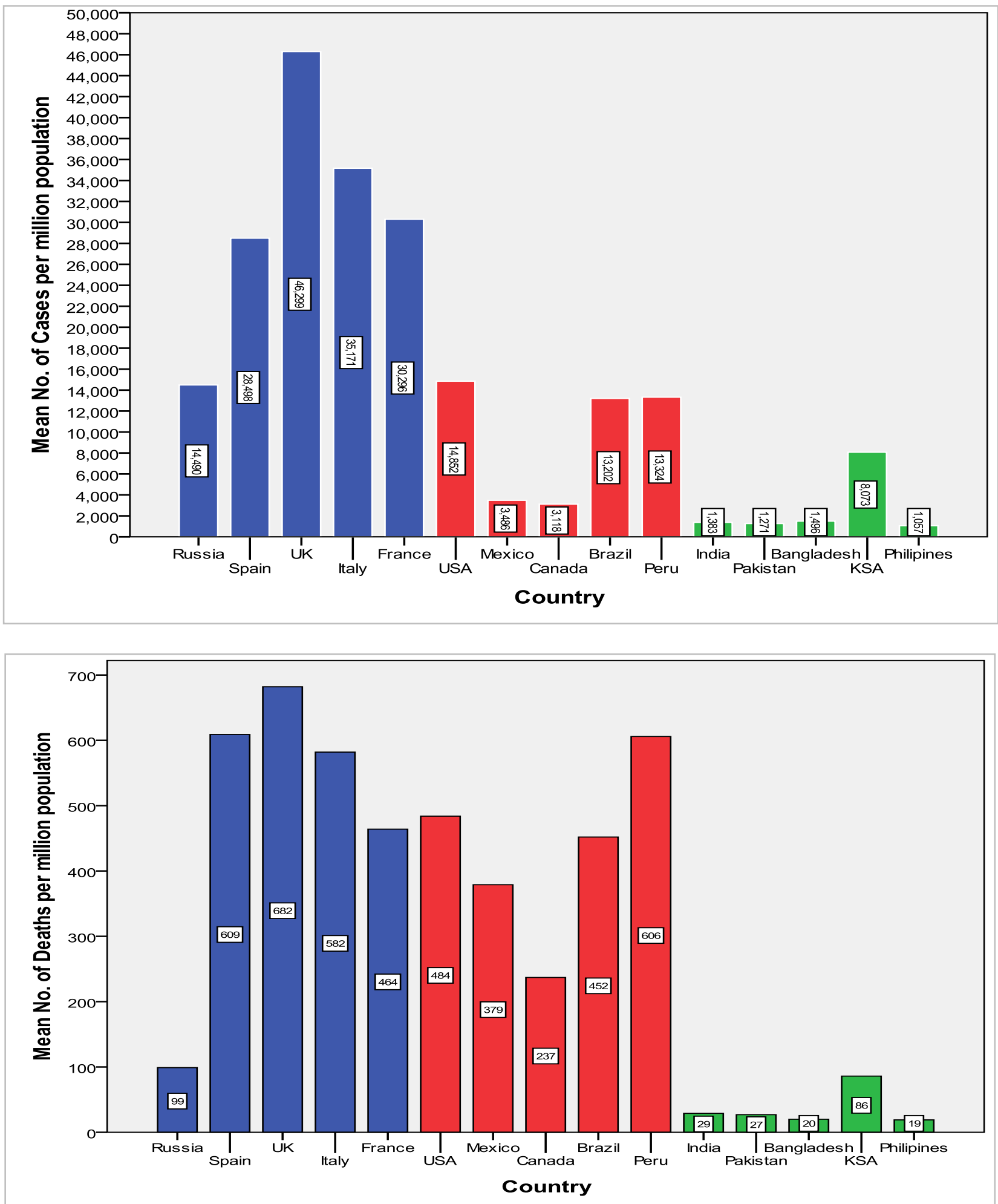

Figure 1: Mean No. of COVID-19 cases and deaths in Europe, America (both north and south) and Asia per million of the population 


\section{Discussion}

Novel coronaviruses might have first originated from animals and now jumped into human species, the possibility of person-toperson transmission could not be excluded ${ }^{[7]}$. Vigilant epidemiological control in the community and healthcare facilities is important to prevent other SARS-like epidemic ${ }^{[8]}$. Significant scientific advances since the Spanish flu's onset 100 years ago foster a false sense of complacency about the ability to combat a nationwide and deadly influenza outbreak. However, in the face of this threat and despite the advent of drugs, protocols, and vaccines available to treat the flu and associated infections, we remain dangerously vulnerable ${ }^{[9]}$.

Although novel coronavirus belongs to the same group as the SARS CoV and MERS family, the infection it causes is different from the previous two types in a way that COVID-19 shows a significantly higher mortality frequency, particularly in patients with advanced chronological age and existing comorbid conditions such as diabetes mellitus, autoimmune disorders, and respiratory and cardiac complaints ${ }^{[10]}$. It has rapidly spread around the world, posing enormous health, economic, environmental, and social challenges to the entire human population ${ }^{[11]}$. Therefore, world communities and healthcare departments around the globe have taken this disease very seriously. For this reason, the world scientific community has joined hands, and several studies are ongoing in the scientific and research institutions regarding the number of cases and mortality ${ }^{[12]}$, mode of spread and epidemic trend in different countries and regions ${ }^{[12-14]}$, signs, symptoms with clinical findings, and laboratory tests ${ }^{[15-18]}$. Furthermore, treatment of the infection and development of an efficient vaccine against the COVID-19 have been discussed previously ${ }^{[19-21]}$. All of the above studies have discussed COVID 19 infection in general, and we could not find substantial evidence of differences in the infection rate in various countries and regions of the world in the form of scientific research studies. In this study, we tried to answer these questions with the aim of exploring the morbidity and mortality patterns of novel coronavirus (COVID-19) infections among the worst affected regions of the world.

With respect to cases and mortality per million people, the COVID-19 pandemic was affected by different intensities between countries and regions. The results of a study suggest that a combination of different testing strategies and host genetic susceptibility contribute to differences in severity of the COVID19 epidemics in the Western Pacific/East Asia and Europe ${ }^{[22]}$.

In our study, we found that the difference between European and Asian countries is significant with respect to the cases and mortality per million of the population. Although European countries are developed, they have better economic conditions ${ }^{[23]}$ and health infrastructure facilities, but the average rate of infection and mortality was significantly higher than that in Asian countries. This indicates that additional factors such as living standards and hygienic conditions may lead to exposure to numerous viruses of similar families, and the development of individual and herd immunity in the population is of utmost importance.

As per the available literature and in formation, the per capita income and living standards in the Asian countries is low and the per square kilometer population in these countries is also higher than that in the European and American regions. These factors might play a role in increasing the chance of exposure to similar viruses and the development of individual and herd immunity in Asian countries.
Differences in host susceptibility may also play a role. We found that Europe had a higher prevalence of the ID/DD-genotypes thought to confer an increased risk for severe COVID-19 than the Western Pacific. However, there was no statistically significant association between ID/DD prevalence and mortality/capita or cases/capita in the country-level analysis ${ }^{[24]}$. The United Kingdom briefly proposed pursuing a strategy of allowing the controlled spread of SARS-CoV-2 to develop 'herd-immunity ${ }^{[25]}$ Individuallevel studies have found that being older and obese were strong risk factors for both severe symptomatic disease and mortality ${ }^{[26]}$.

Ecological analysis in a study found positive associations between these two variables and COVID-19 mortality. These findings suggest that a higher prevalence of the elderly and possibly obesity may explain some of the differences in COVID-19 mortality ${ }^{[24]}$. Similarly, in this study, the European and American regions have higher elderly and obese population ${ }^{[27]}$ and are more affected than the Asian countries. This suggests that factors other than better healthcare services and economic conditions play a significant role.

Anders Tagnell ${ }^{[28]}$ established in a news article that Denmark and Finland have 55 and 14 fatalities per million of their populations, respectively, compared to Sweden's fatality rate, which was 131 per million of the population. Similarly, Promohammad et al ${ }^{[29]}$. have reported that the mortality rate in COVID 19 confirmed cases is lower than in SARS - and MERSinfected patients. They further stated that clinical outcomes and findings would be biased by reporting only confirmed cases, and this should be considered when interpreting the data.

Pandemics not only interrupt healthcare operations but also disrupt the provision of critical and emergency care to critically sick patients ${ }^{[30]}$. Preparing the public for potential pandemics such as a novel coronavirus infection is an essential component of a healthcare system and businesses that provide critical healthcare services. Although many healthcare institutions and business organizations have a pandemic plan to continue their services during the recent outbreak of COVID-19 and few have already updated their plans accordingly.

It is known that every outbreak is accompanied by a tsunami of information, but within the information we always have misinformation, and during an outbreak, communities should take steadfast actions to mitigate its impact by obtaining correct information ${ }^{[1]}$. Since the level of virus penetration is not measurable, it causes severe panic, anxiety, and fear among the general public. Therefore, providing the right information from a reliable source is a key issue in a pandemic like COVID-19. This is our understanding that the results of the present study would help worst-hit regions and countries review their pandemic plans and be prepared in case this epidemic expands and affects more individuals and society as a whole, although different countries will need different approaches focusing on its humanitarian nature and available resources. This would help to reduce the fear of ailment and death.

Although COVID-19 initially started in the Hubei province of China, we did not include China amongst the worst hit countries of the world. From our analysis, it was observed that China's efforts in early control of the disease were a combination of strong governance, strict regulation, and spontaneous community/citizen participation. Due to all these efforts, even with a huge population, China did not reach to our criteria i.e., at least 500 cases per million of a population. Worst-hit regions need to learn from China, and similar efforts are needed by other countries to reduce the COVID-19 crisis. 
In comparison with the Spanish flu pandemic, a century ago in 1918, which accounted for about 50 to 100 million deaths globally ${ }^{[31]}$ until now COVID-19 accounted for 1,079,029 deaths out of the 7.8 billion global population since its outbreak in over 100 countries/territories as reported by the latest statistics of WHO on October $2020^{[32]}$. These differences in the epidemiological parameters of pandemic could be related to the advancement in public health and healthcare systems worldwide over time. However, even a century after the Spanish flu, there were subsequent infection outbreaks, such as SARS and MERS. As a result, the global population is complicated by health and economic challenges ${ }^{[33]}$. As highlighted in the literature, comparing the epidemiological parameters COVID-19, Spanish flu, and other infection outbreaks such as SARS and MERS can support policymakers in evidence-based decision-making for effective pandemic readiness ${ }^{[34]}$. Therefore, it is recommended that further comprehensive research is required to establish the causes of high infection rates and mortality due to viral infections such as COVID-19.

\section{Conclusions}

This study concludes that the infection rate and mortality are higher in European and American countries than in developing Asian countries. The distinguishable causes of increase in infection rate and mortality in developed European and American countries may be due to differences in individual and herd immunity in the population due to less exposure to similar viruses. This lack of exposure may be attributed to better economic conditions leading to good hygienic practices as compared to the developing and underdeveloped countries of Asia.

The second cause may be more elderly and obese populations in Europe and America than in Asia. A detailed study is needed to determine the causes of high infection rate and mortality of COVID-19 in developed countries, compared to developing countries, especially focusing on the development of herd immunity and exposure to other viruses. This will help countries review their pandemic control program and plan appropriate measures to decrease the infection and mortality rates, which will help reduce stress, anxiety, and depression among the people.

\section{Limitations}

1. Measures of age structure and obesity are relatively crude and may not have fully captured the risk differences between populations.

2. Differences in lock-down, quarantine, social-distancing, or face mask usage may play a role. There were considerable differences in how these strategies were applied in countries.

3. Another limitation is that the number of cases and deaths that would occur in the impending second wave of the COVID-19 infections in many countries in these regions cannot be included in the study as the data are frequently changing.

Finally, this study focuses on various important factors involved in controlling the COVID -19 spread other than the economic conditions, better health care infrastructure, and facilities, as available in western countries. These factors may include large population living per square kilometer, poor economy, and unhygienic conditions may lead to exposure to various similar viruses and the development of individual and herd immunity in Asian countries. This may be a blessing in disguise for countries in Asian regions that needs to be investigated carefully based on clinical and laboratory research findings.

\section{Ethics approval and consent to participate}

This study was conducted at the Basic Sciences Department, College of Medicine, Dar Al Uloom University (IRB Approval number: Pro21010010). Data on the incidence and mortality due to the COVID-19 pandemic were acquired from the World Health Organization, countries and regions and their concerned ministries and Worldometer; hence, informed consent was not required.

\section{Abbreviations}

COVID-19: novel coronavirus infections

CDC: Centers for Disease Control and Prevention

ISI: Institute of Scientific Information

SARS-CoV-2: coronavirus 2

PHEIC: Public Health Emergency of International Concern

SARS: severe acute respiratory syndrome

MERS: Middle East Respiratory Syndrome

\section{Data availability}

The data on the worldwide pandemic of COVID-19 were obtained from World Health Organization (WHO) (https://covid19.who.int/explorer), John Hopkin's University research center (https://coronavirus.jhu.edu/map.html), Worldometer, Centers for Disease Control and Prevention (CDC) (https://www.worldometers.info/coronavirus/).

\section{Conflicts of interest}

The authors declare that there is no conflict of interest regarding the publication of this paper.

\section{Funding}

This research was financially supported by the Deanship of Research Dar Al Uloom University, Riyadh, Saudi Arabia (grant number: Pro21010010).

\section{Authors' contributions}

AH was responsible for conceptualization and supervision. SWK conducted data curation and formal analysis. SK was responsible for investigation and visualization. MK devised the methodology, was responsible for project administration, validation and writing the original draft

MA, MTA were responsible for resources. SA was responsible for software. MMK, MK performed the writing - review \& editing and TA conducted the funding acquisition.

\section{References}

[1] George PM, Wells AU, Jenkins G. Pulmonary fibrosis and COVID-19: the potential role for antifibrotic therapy. Lancet Respir Med. 2020; 8(8):807-815.

[2] World Health Organization. WHO timeline - COVID-19 [Internet]. 2020. Available from: 
https://www.who.int/news/item/27-04-2020-who-

timeline---covid-19. Accessed on 12 July 2020.

[3] Cao J, Tu WJ, Cheng W, Yu L, Liu YK, Hu X, et al. Clinical features and short-term outcomes of 102 patients with corona virus disease 2019 in Wuhan, China. Clin Infect Dis. 2020; 71(15):748-755.

[4] Sargiacomo C, Sotgia F, Lisanti MP. COVID-19 and chronological aging: senolytics and other anti-aging drugs for the treatment or prevention of corona virus infection? Aging (Albany NY). 2020; 12(8):6511-6517.

[5] Okyere MA, Forson R, Essel-Gaisey F. Positive externalities of an epidemic: The case of the coronavirus (COVID-19) in China. J Med Virol. 2020; 92(9):13761379.

[6] Prajapat M, Sarma P, Shekhar N, Avti P, Sinha S, Kaur $\mathrm{H}$, et al. Drug targets for corona virus: A systematic review. Indian J Pharmacol. 2020; 52(1):56-65.

[7] Su S, Wong G, Shi W, Liu J, Lai ACK, Zhou J, et al. Epidemiology, genetic recombination, and pathogenesis of coronaviruses. Trends Microbiol. 2016; 24(6):490502 .

[8] Chan JF, Yuan S, Kok KH, To KK, Chu H, Yang J, et al. A familial cluster of pneumonia associated with the 2019 novel coronavirus indicating person-to-person transmission: a study of a family cluster. Lancet. 2020; 395(10223):514-523.

[9] Greenberger M. Better prepare than react: Reordering public health priorities 100 years after the Spanish flu epidemic. Am J Public Health. 2018; 108(11):14651468.

[10] Siddamreddy S, Thotakura R, Dandu V, Kanuru S, Meegada S. Corona Virus Disease 2019 (COVID-19) presenting as acute ST elevation myocardial infarction. Cureus. 2020; 12(4):e7782.

[11] Chakraborty I, Maity P. COVID-19 outbreak: Migration, effects on society, global environment and prevention. Sci Total Environ. 2020; 728:138882.

[12] Zhu ZB, Zhong CK, Zhang KX, Dong C, Peng H, Xu T, et al. [Epidemic trend of COVID-19 in Chinese mainland]. Zhonghua Yu Fang Yi Xue Za Zhi. 2020; 54(6):620-624. Chinese.

[13] Yang HY, Duan GC. [Analysis on the epidemic factors for COVID-19]. Zhonghua Yu Fang Yi Xue Za Zhi. 2020; 54(6):608-613. Chinese .

[14] Special Expert Group for Control of the Epidemic of Novel Coronavirus Pneumonia of the Chinese Preventive Medicine Association. [An update on the epidemiological characteristics of novel coronavirus pneumonia (COVID-19)]. Zhonghua Liu Xing Bing Xue Za Zhi. 2020; 41(2):139-144. Chinese.

[15] Hase R, Kurita T, Muranaka E, Sasazawa H, Mito H, Yano Y. A case of imported COVID-19 diagnosed by PCR-positive lower respiratory specimen but with PCRnegative throat swabs. Infect Dis (Lond). 2020; 52(6):423-426.

[16] Zhu T, Wang Y, Zhou S, Zhang N, Xia L. A comparative study of chest computed tomography features in young and older adults with corona virus disease (COVID-19). J Thorac Imaging. 2020; 35(4):W97-101.

[17] Konrad R, Eberle U, Dangel A, Treis B, Berger A, Bengs $\mathrm{K}$, Fingerle $\mathrm{V}$, et al. Rapid establishment of laboratory diagnostics for the novel coronavirus SARS-CoV-2 in
Bavaria, Germany, February 2020. Euro Surveill. 2020; 25(9):2000173.

[18] Das KM, Lee EY, Al Jawder SE, Enani MA, Singh R, Skakni L, et al. Acute Middle East Respiratory Syndrome Coronavirus: Temporal lung changes observed on the chest radiographs of 55 patients. AJR Am J Roentgenol. 2015; 205(3):W267-74.

[19] Talreja H, Tan J, Dawes M, Supershad S, Rabindranath $\mathrm{K}$, Fisher J, et al. A consensus statement on the use of angiotensin receptor blockers and angiotensin converting enzyme inhibitors in relation to COVID-19 (corona virus disease 2019). N Z Med J. 2020; 133(1512):85-87.

[20] Cook TM, El-Boghdadly K, McGuire B, McNarry AF, Patel A, Higgs A. Consensus guidelines for managing the airway in patients with COVID-19: Guidelines from the Difficult Airway Society, the Association of Anaesthetists the Intensive Care Society, the Faculty of Intensive Care Medicine and the Royal College of Anaesthetists. Anaesthesia. 2020; 75(6):785-799.

[21] Luo H, Tang QL, Shang YX, Liang SB, Yang M, Robinson N, et al. Can Chinese medicine be used for prevention of Corona Virus Disease 2019 (COVID-19)? A Review of historical classics, research evidence and current prevention programs. Chin J Integr Med. 2020; 26(4):243-250.

[22] Kenyon C. Why has COVID-19 spread more extensively in europe than Asia? [Internet]. Preprints 2020, 2020050200. doi: 10.20944/preprints202005.0200.v1.

[23] The World Bank. Population ages 65 and above (\% of total population) [Internet], 2020. Available from: https://data.worldbank.org/indicator/SP.POP.65UP.TO.Z S. Accessed on 4 August 2020.

[24] World Health Organization. Prevalence of obesity among adults, BMI $\geq 30$, age-standardized estimates by country [Internet], 2020. Available from: https://apps.who.int/gho/data/view.main.CTRY2450A?la $\mathrm{ng}=\mathrm{en}$. Accessed on 6 August 2020.

[25] Kenyon C. Why has COVID-19 mortality been higher in certain countries than others? an ecological analysis of 204 countries. Preprints 2020, 2020060246. doi: 10.20944/preprints20200s6.0246.v1.

[26] Hunter DJ. Covid-19 and the Stiff Upper Lip - The Pandemic Response in the United Kingdom. N Engl J Med. 2020; 382(16):e31.

[27] Richardson S, Hirsch JS, Narasimhan M, Crawford JM, McGinn $\mathrm{T}$, Davidson $\mathrm{KW}$, et al. Presenting characteristics, comorbidities, and outcomes among 5700 patients hospitalized with COVID-19 in the New York City area. JAMA. 2020; 323(20):2052-2059.

[28] Paterlini M. 'Closing borders is ridiculous': the epidemiologist behind Sweden's controversial coronavirus strategy. Nature. 2020; 580(7805):574.

[29] Pormohammad A, Ghorbani S, Khatami A, Farzi R, Baradaran B, Turner DL, et al. Comparison of confirmed COVID-19 with SARS and MERS cases - Clinical characteristics, laboratory findings, radiographic signs and outcomes: A systematic review and meta-analysis. Rev Med Virol. 2020; 30(4):e2112.

[30] Xiong Z, Fu L, Zhou H, Liu JK, Wang AM, Huang Y, et al. [Construction and evaluation of a novel diagnosis pathway for 2019-Corona Virus Disease]. Zhonghua Yi Xue Za Zhi. 2020; 100(16):1223-1229. Chinese. 
[31] Ashton J. COVID-19 and the 'Spanish' flu. J R Soc Med. 2020; 113(5):197-198.

[32] Worlds Health Organization. WHO Coronavirus Disease (COVID-19) Dashboard [Internet], 2020. Available from: https://covid19. who.int/?gclid=Cj0KCQiA3YABhCnARIsAKYDH7tjJ_kBi1dehFnGOAkcegVToZZ4 xkhrjhm4Yn9S7IDdoINM4EbhPM4aAh_LEALw_wcB. Accessed on 6 August 2020.

[33] Park M, Cook AR, Lim JT, Sun Y, Dickens BL. A systematic review of COVID-19 epidemiology based on current evidence. J Clin Med. 2020; 9(4):967.

[34] He D, Zhao S, Li Y, Cao P, Gao D, Lou Y, et al. Comparing COVID-19 and the 1918-19 influenza pandemics in the United Kingdom. Int J Infect Dis. 2020; 98:67-70 . cc (i) Open Access This article is licensed under a Creative Commons Attribution 4.0 International License, which permits use, sharing, adaptation, distribution and reproduction in any medium or format, as long as you give appropriate credit to the original author(s) and the source, provide a link to the Creative Commons license, and indicate if changes were made. The images or other third party material in this article are included in the article's Creative Commons license, unless indicated otherwise in a credit line to the material. If material is not included in the article's Creative Commons license and your intended use is not permitted by statutory regulation or exceeds the permitted use, you will need to obtain permission directly from the copyright holder. To view a copy of this license, visit https://creativecommons.org/licenses/by/4.0/.

(C) The Author(s) 2021 